\title{
Use of antibiotics in veterinary practice
}

The use of antibiotics in animals has many similarities with their use in man, especially when considering family pets. The same, however, cannot be said of live-stock bred for food (e.g., pigs and poultry) and competition animals (e.g., racehorses and pigeons), partly because of the inherent business profit element, but most of all because of the need to apply medication on a herd or flock basis, especially with farm animals managed under intensive husbandry systems. ${ }^{1}$ Unfortunately, confusion and misunderstandings have arisen from statements and writings by instant media experts and by others who do not understand the agricultural and veterinary use of antimicrobial agents so that the general public as well as the medical and allied professions are confused about the real situation. The issues involved in the veterinary and agricultural use of antibiotics have been reviewed in detail elsewhere. ${ }^{2}$

\section{Legal controls on antibiotics for non-human use}

All antibiotics are tested under the Medicines Act (1968) in respect of purity, safety and efficacy. If the data provided are satisfactory, then a licence will be issued allowing the use of the product according to the conditions on the official data sheet. As in human medicine, antibiotics are prescription-only products and they can be obtained only from the vet who has the animal under his care. ${ }^{3}$ Antibiotics cannot be bought over the counter from the pet shop or agricultural merchant. The reporting of suspect adverse reactions is also required. Meat animal carcasses are checked for antimicrobial residues and, if present, a financial penalty is imposed; the Royal British Pharmaceutical Society visits farms and monitors compliance with antibiotics-in-feed regulations. In addition there is a stated withdrawal period for each antibiotic which must be observed before any farm animal is sent for slaughter.

\section{Use of antibiotics in companion animals}

In most cases antibiotic medication is limited to the individual pet animal or bird, but there will be instances when mother and offspring will all be treated at the same time. The same will apply to a tank of fish or pen of birds. Generally, this group of animals or birds will get their antibiotics in water, in feed or by injection. The subject of tissue residues does not apply and any risk for man will be related to cross-infection with zoonotic bacteria causing infection in the pets.

\section{Use of antibiotics in food producing animals}

This is perhaps the most controversial of all antibiotic applications and also the most misunderstood by consumers of animal meats who are nonveterinary and non-agriculturally minded. It is important, therefore, to clarify several misunderstandings. ${ }^{1}$ Any agricultural enterprise must be financially viable and able to yield margins of profit comparable to those expected from traditional financial investment programmes. Budgets and targets that are set demand the lowest level of mortality and the minimum morbidity. Such financial constraints do not apply in human medicine. ${ }^{2}$ Animals or poultry are usually kept in groups of varying sizes so that the whole group will share a common air space and will be in constant contact with faeces and urine. It is self evident that if one animal shows early signs of infection, there is a very high probability that at least the majority of the remainder will have been infected at the same time. It is, therefore, common sense to give medication to the whole group and treat it as one would a single animal. This applies if the group size is 20 or 20000 because the source of infection and the time of infection would be the same. ${ }^{3}$ Modern strains of pigs and poultry do not receive antibiotics on a daily basis in order to stay alive. Pharmaceutical grade antibiotics are very expensive and with the very low profit margins in the agricultural sector it would not make economic sense if the cost of the antibiotic used exceeded the gross profit margin on the animal when slaughtered. It must also be remembered that current breeds of poultry and pigs grow very rapidly and are ready for slaughter in about 46 days and 4 months respectively; most will reach the retail shop without having had any antibiotics during their lifetime. Recent figures from the UK on antimicrobial residue testing show that, of almost 42000 random samples taken, only $0.4 \%$ were found to be above the minimum residue level. These figures clearly show that if antibiotics are being administered then the correct withdrawal period is being applied and, more importantly, that animals are not being given antimicrobial agents right up to the day of slaughter. ${ }^{4}$ Antibiotic-resistant bacteria of animal origin do not present a significant hazard for man. Linton ${ }^{4}$ indicated that while antibiotic-resistant Escherichia coli reach man from animal sources and colonise the human gut for a number of days, there is no evidence to incriminate these strains as a cause of non-specific coliform infections in man. The question that follows from this is: does the human gut become 
colonised or are the organisms just passing through? If the latter, it is not surprising that these bacteria do not transfer resistance plasmids to the indigenous gut flora. Undoubtedly the major cause of antibioticresistant bacteria in the intestines is the direct use of antibiotics in that species and this applies to man as well as animals. The prevalence of zoonotic transfer of antibiotic-resistant bacteria from animals to man is not at all clear. There is some evidence of human infection with certain phage types of salmonellae in relation to food poisoning, but it is often uncertain how these strains have reached man. ${ }^{4}$ The general lack of data in this area may be one indication that transfer is infrequent, because bacteria do not seem generally able to become established in the intestines of unrelated species. Results from my laboratory tend to support this argument in that antibiotic-resistant bacteria from calves could not be established in the intestines of poultry, turkeys or pigs. ${ }^{5}$ It is highly likely that the physiological barriers present in man, animals and birds prevent the successful colonisation by bacteria from an unrelated animal species, whether the bacteria are antibiotic-resistant or not.

\section{References}

1. Walton J R. Antibiotic resistance: an overview. Vet Rec 1988; 122: 249-251

2. Walton J R. Antibiotics, animals, meat and milk. Zentralbl Vet Med A 1983; 30: 81-92.

3. Anon. Prescribing of medicinal products by veterinary surgeons. Vet Rec 1991; 129: 245-248.
The position with regard to antibiotic-resistant bacteria in the environment is less clear. The spreading of animal slurry and manures on farm land has been blamed for the contamination of natural waters and the environment in general, but it should also be remembered that vast quantities of human sewage sludge are similarly disposed of on agricultural land. In this context, mention is seldom made of the destruction of bacteria by natural elements, such as UV light and desiccation, or the role of naturally occurring antibiotics produced by bacteria as a normal part of their metabolism. There is a continual removal of bacteria from the environment to balance those that are added to it, and this applies to resistant and sensitive bacteria alike. This homeostatic mechanism is often overlooked, as is the fact that we and our animals cannot survive in this environment without frequent and extensive contact with micro-organisms.

Department of Veterinary Clinical Science,

J. R. WALTON

University of Liverpool,

Leahurst, Neston,

South Wirral L64 7TE

4. Linton A H. Antibiotic resistance in bacteria associated with animals and their importance to man. J Antimicrob Chemother $1985 ; 15$ : $385-386$.

5. Hunter J E B, Shelly J C, Walton J R, Hart C A, Bennett M. Apramycin resistance plasmids in Escherichia coli: possible transfer to Salmonella typhimurium in calves. Epidemiol Infect 1991 ; (in press). 